\title{
Costs in the Treatment of Schizophrenia in Adults Receiving Atypical Antipsychotics: An 11-Year Cohort in Brazil
}

\author{
Wallace Breno Barbosa ${ }^{1,2}$. Juliana de Oliveira Costa ${ }^{2,3}$. Lívia Lovato Pires de Lemos ${ }^{2,3} \cdot$ Rosângela Maria Gomes $^{1,2}$. \\ Helian Nunes de Oliveira ${ }^{3}$. Cristina Mariano Ruas ${ }^{1}$. Francisco de Assis Acurcio ${ }^{1,2}$. Corrado Barbui ${ }^{4}$. \\ Marion Bennie ${ }^{5}$ Brian Godman ${ }^{5,6,7,8}$. Augusto Afonso Guerra Jr ${ }^{1,2}$
}

Published online: 27 July 2018

(c) The Author(s) 2018

\begin{abstract}
Background Schizophrenia is associated with significant economic burden. In Brazil, antipsychotic drugs and outpatient and hospital services are provided by the Brazilian National Health System (SUS) for patients with schizophrenia. However, few studies capture the cost of managing these patients within the Brazilian NHS. This is important to appraise different management approaches within universal healthcare systems.

Objective Our objective was to use real-world data to describe the costs associated with the treatment of schizophrenia in adults receiving atypical antipsychotics in Brazil from 2000 to 2010.

Methods We integrated three national databases for adult patients with schizophrenia receiving one or more atypical antipsychotics. We assessed only direct medical costs and the study was conducted from a public-payer perspective. A multivariate log-linear regression model was performed to evaluate associations between costs and clinical and demographic variables. Results We identified 174,310 patients with schizophrenia, with mean \pm standard deviation (SD) annual costs of \$US1811.92 \pm 284.39 per patient. Atypical antipsychotics accounted for $79.7 \%$ of total costs, with a mean annual cost per patient of \$US1578.74 \pm 240.40 . Mean annual costs per patient were $\$$ US2482.90 \pm 302.92 for psychiatric hospitalization and \$US862.96 \pm 160.18 for outpatient psychiatric care. Olanzapine was used by $47.7 \%$ of patients and represented $62.8 \%$ of the total costs of atypical antipsychotics. Patients who used clozapine had the highest mean annual cost per patient for outpatient psychiatric care and psychiatric hospitalization.

Conclusions Atypical antipsychotics were responsible for the majority of the schizophrenia treatment costs, and psychiatric hospitalization costs were the highest mean annual cost per patient. Authorities should ensure efficient use of atypical antipsychotics and encourage outpatient psychiatric care over psychiatric hospitalization where possible.
\end{abstract}

Electronic supplementary material The online version of this article (https://doi.org/10.1007/s40258-018-0408-4) contains supplementary material, which is available to authorized users.

\section{Brian Godman}

brian.godman@strath.ac.uk; Brian.Godman@liverpool.ac.uk;

Brian.Godman@ki.se

Extended author information available on the last page of the article

\section{Key Points for Decision Makers}

Atypical antipsychotics were the largest contributor (approximately $80 \%$ ) to direct medical costs for patients with schizophrenia in this Brazilian cohort, with psychiatric hospitalization accounting for the largest cost category per patient. However, costs of atypical antipsychotics will fall as generics become increasingly available.

It is essential that health services seek to optimize the use of atypical antipsychotic medicines and outpatient services to maximise patient care within finite resources. 


\section{Introduction}

Schizophrenia is a severe and debilitating mental disorder that affects approximately $0.3-0.7 \%$ of the population [1] and is one of the leading causes of years lived with disability worldwide [2]. People with schizophrenia present changes in thinking, feeling, and behaviour. Its manifestations are usually divided into positive symptoms (e.g. hallucinations and delusions), negative symptoms (e.g. diminished emotional expression and lack of motivation) $[1,3,4]$ and cognitive symptoms (e.g. problems with working memory and executive functioning) [3], but no single symptom is pathognomonic of the disorder [1].

Schizophrenia is associated with a significant economic burden. In the USA, estimated costs of \$US62.7 billion were related to the disease in 2002, reaching \$US155.7 billion in 2013. This included direct costs related to the care of the disorder, including hospital inpatient stays, emergency room visits, outpatient visits and prescription medicines. Direct non-healthcare costs and mental disorder-related indirect costs are also substantial $[5,6]$. The mean monthly costs per patient on treatment with schizophrenia is typically more than four times higher than those for the population as a whole with similar demographics but without schizophrenia [7].

The treatment of schizophrenia generally includes antipsychotic medicines, increasingly atypical antipsychotics, coupled with psychological and psychosocial interventions [3, 8]. The Brazilian National Health System [NHS (Sistema Único de Saúde; SUS)] provides-in addition to hospital and outpatient care-typical antipsychotics, or first-generation antipsychotics, such as chlorpromazine and haloperidol, and atypical antipsychotics, or second-generation antipsychotics (SGA), in oral formulations. This includes oral clozapine, olanzapine, quetiapine, risperidone and ziprasidone but not-for instance-aripiprazole, long-acting atypical antipsychotics or injectable atypical antipsychotics. These SGAs are considered high-cost or specialized medicines and are dispensed to patients after an analysis of compliance as required by the national clinical guidelines for the treatment of schizophrenia [9-12]. This strategy aims to rationalize treatment resource utilization for both medical and financial reasons [13]. For patients meeting the requirements, SGAs are fully funded by the SUS (public payer), otherwise the prescribed medicines are fully funded by the patients themselves.

Several studies have shown that medicine costs account for approximately $25 \%$ of direct costs related to the treatment of schizophrenia [5-7, 14], highlighting the importance of antipsychotic medicines when evaluating different management approaches for patients with schizophrenia
$[7,14]$. In Brazil, a study performed from the SUS national database between 2000 and 2004 reported olanzapine and risperidone were among the highest cost medicines most dispensed, accounting for $8.6 \%$ of annual expenditure on high-cost drugs [15]. From August 2012 to July 2013, the SUS spent an estimated \$US181 million [converted using the purchasing power parity (PPP) conversion factor of the World Bank of 2012, \$US1 = 1.559 Brazilian Real (BRL)] [16] on atypical antipsychotics alone, representing $7.3 \%$ of the total amount spent on high-cost drugs in Brazil during that period [12]. Other Brazilian studies have evaluated the costs associated with the use of antipsychotics, albeit with considerable methodological heterogeneity and with different objectives [17-19].

Considering the impact of schizophrenia on the patient and society, and the need to understand the allocation of health resources for the treatment of this mental disorder within a universal healthcare system with finite resources, our objective was to describe the costs associated with the treatment of schizophrenia in adults receiving atypical antipsychotics through real-world data. In this way, we aimed to gain an accurate picture of actual costs rather than relying on modelling approaches to compile the resource picture.

\section{Methods}

\subsection{Study Design and Population}

This study is an evaluation of the costs associated with the use of high-cost drugs and outpatient and hospital services in Brazil through a national non-concurrent open cohort of adult patients with schizophrenia receiving atypical antipsychotics, from January 2000 to December 2010. The time period of the cohort was determined by the data available within the SUS national administrative databases. Atypical antipsychotics were chosen because of the requirements for their funding within the SUS and their current contribution to expenditure on high-cost drugs in Brazil. Clozapine, olanzapine and risperidone have been available in the SUS since the second half of the 1990s [20-23], and quetiapine and ziprasidone were incorporated into the SUS in 2002 [9, 10]. The first generic risperidone was available in Brazil in 2004, with generic clozapine, olanzapine and quetiapine available in the second half of 2010 and generic ziprasidone in 2013 [24].

This cohort was built via integration through deterministic-probabilistic linkage records from the Mortality Information System (SIM) and two SUS national administrative databases: (1) the Ambulatory Information System (SIA/ SUS), which includes data on outpatient procedures and provision of high-cost drugs, and (2) the Hospital Information System (SIH/SUS). The linkage aims to find records 
for the same patient in different files and unify them as a single record in a database. Deterministic linkage is used when records are reliable and able to be compared, whereas probabilistic linkage is used when records have problems of consistency, errors or undeclared information [25]. This methodology has been described in other studies [25-28].

Patients were included if they (1) received one or more of the following atypical antipsychotics: clozapine [anatomical therapeutic chemical (ATC) code: N05AH02], olanzapine (N05AH03), quetiapine (N05AH04), risperidone (N05AX08) or ziprasidone (N05AE04); (2) were diagnosed with one of the following diseases according to the International Statistical Classification of Diseases and Related Health Problems, Tenth Revision (ICD-10): paranoid schizophrenia (F20.0), hebephrenic schizophrenia (F20.1), catatonic schizophrenia (F20.2), undifferentiated schizophrenia (F20.3), post-schizophrenic depression (F20.4), residual schizophrenia (F20.5), simple schizophrenia (F20.6) or other schizophrenia (F20.8); and (3) were treated between January 2000 and December 2010. These atypical antipsychotics were chosen as they are currently available via the SUS. The exclusion criteria were (1) patients taking atypical antipsychotics drugs for other ICD-10 codes, (2) patients aged $<18$ years and (3) patients who have not received atypical antipsychotics for at least 12 months, continuously or not, during the 11-year follow-up. All patients who met the inclusion criteria and not the exclusion criteria were included in the cohort.

Entry date was defined as the date of the first registration of dispensing of an atypical antipsychotic drug in the SIA, and the date of the loss to follow-up was defined as the date of the last patient record in the SIA or SIH, death (SIM) or 31 December 2010 (censoring right).

\subsection{Cost Analysis}

The SIA processes all production of outpatient care or dispensing of high-cost drugs, and the SIH processes all production related to patient care in hospitals. The term production refers to procedures that are performed during patient care, which may include materials and drugs used, health professionals involved and hotel structure in case of hospitalization. Consequently, each procedure or high-cost drug used and registered for each individual in the SUS national databases (SIA and SIH) brings with it some information such as description of the procedure and its value or highcost drug for use in 30 days and its value [29, 30].

In Brazil, high-cost drugs refer to those for chronic diseases, whose unit costs or costs of all treatment are considered high [13], which includes the atypical antipsychotics. In our study, outpatient procedures comprise both outpatient psychiatric care (e.g. Psychosocial Care
Center) and other outpatient care such as outpatient non-psychiatric care to which patients may have access. Finally, hospital procedures include psychiatric hospitalizations in a general or psychiatric hospital and other hospitalizations, which were defined as non-psychiatric hospitalization.

All financial resources from the outpatient or hospital procedures and the high-cost drugs used by the patient were summed to calculate the total cost for the study period. In other words, a micro-cost approach (bottom-up costing) [31] was used to estimate the direct healthcare costs with respect to high-cost drugs and outpatient and hospital procedures from the SUS databases (SIA and SIH) used by each patient with schizophrenia.

Monetary values were adjusted using the PPP conversion factor of the World Bank. PPP rates have an annual periodicity and provide a standard measure with which expenditure levels can be compared between countries. We adjusted the cost values of each year using the PPP rate for that respective year, i.e. for cost values of the year 2000 , we used the year 2000 PPP rate: $\$$ US1 $=0.759 \mathrm{BRL}$; in 2001: \$US $1=0.803 \mathrm{BRL}$, and so on [16]. The cost analysis was from a public-payer perspective, according to Brazilian Ministry of Health recommendations [31].

The Brazilian NHS is financed by the federal government, states and municipalities. In addition, citizens also participate directly in health financing when using the private health system, through health insurance, co-payment or directly paying for the medicine or health procedure. The federal government is the main funder of the public health system in Brazil, and the high-cost drugs and procedures registered in the SUS databases (SIA and SIH) used in this study are funded by the federal government [32].

Individual costs were characterized by sex, age group, geographic region of residence, primary diagnosis (ICD10), first atypical antipsychotic used and period of study entry. Moreover, we also characterized costs by type of end of follow-up (censoring or death), psychotic outbreak, drug switching (change of atypical antipsychotic during follow-up) and cause of death. Censoring and death report how the patient's follow-up ended, i.e. censoring right, censoring due to the last record and no patient return to cohort or death. Psychotic outbreaks were defined according to the patient's psychiatric hospitalization record.

Subsequently, we stratified the individual costs by procedure category (atypical antipsychotics, other highcost drugs dispensed, outpatient psychiatric care, other outpatient care, psychiatric hospitalizations and other hospitalizations) and distributed these categories by their follow-up year. Finally, considering the intention-to-treat (ITT) perspective, we grouped costs according to procedure category by the atypical antipsychotic at study entry. 


\subsection{Statistical Analysis}

Demographic (sex, age, geographic region and period at study entry) and clinical [primary diagnosis (ICD-10) at study entry, atypical antipsychotic at study entry, events, end of follow-up and cause of death] variables were described as frequencies, measures of central tendency (mean) and variability \pm standard deviation (SD). The relative proportions of the total costs were calculated for each procedure category. The individual costs were described based on measures of central tendency, (mean and median) annual cost per patient, and variability $\pm \mathrm{SD}$ and interquartile range (IQR).

A multivariate log-linear regression model was performed to evaluate associations between the mean annual cost per patient and clinical and demographic variables. Variables with $p \leq 0.20$ in the univariate analysis were selected to start multivariate modelling with sequential deleting of each variable until only those with $p<0.05$ remained in the final model. For the identification of comorbidities, we used the indicators developed by Elixhauser et al. [33] and updated by Quan et al. [34]. The adequacy of the final model was verified by residuals profile analysis, and our results are presented in the Table $\mathrm{S} 1$ in the electronic supplementary material $(\mathrm{ESM})$ and as percentage differences (PDs) $[\mathrm{PD}=$ $\left.\left(\mathrm{e}^{\mathrm{Ln}(\text { Regression Coeff. })}-1\right) \times 100\right]$ and $95 \%$ confidence intervals.

Statistical analysis was performed using Microsoft Excel (Microsoft Corporation, Redmond, WA, USA), MySQL 5.5 database management system (Oracle Corporation, Redwood, CA, USA) and R Program 3.4.2 (R Core Team 2017, Vienna, Austria).

\subsection{Ethical Approval}

This study was approved by the Ethics Committee of the Federal University of Minas Gerais, Brazil (no. 1072253/2015).

\section{Results}

\subsection{Patient Characteristics}

During the 11-year follow-up period, we identified 174,310 patients with schizophrenia who used atypical antipsychotics provided by the SUS, with a mean \pm SD annual cost of \$US1811.92 \pm 284.39 per patient. The mean age at study entry was $42.7 \pm 17.5$ years (male $38.9 \pm 16.1$; female 46.8 \pm 18.1 ), and the median was 40 years; $63.0 \%$ of the population was aged $18-45$ years; $51.7 \%$ were male; and $64.4 \%$ lived in the Southeast region of Brazil. The mean annual cost per patient was highest between 18 and 45 years of age at study entry. In addition, the mean annual cost per patient was higher for men (\$US1914.84 \pm 304.74 ) and for individuals residing in the Southeast region (\$US1867.57 \pm 287.10). In this cohort, $44.7 \%$ of patients entered the study from 2004 to 2007, but the highest mean annual cost per patient (\$US1957.62 \pm 359.46 ) was for patients who entered the study from 2000 to 2003 (Table 1).

In the present study, $66.5 \%$ of individuals were diagnosed with paranoid schizophrenia (F20.0). However, patients diagnosed with residual schizophrenia (F20.5) had the highest mean annual cost per patient (\$US1925.06 \pm 347.96). The most dispensed atypical antipsychotic at study entry was olanzapine (37.1\%), followed by risperidone (36.3\%), quetiapine $(12.9 \%)$, ziprasidone $(8.0 \%)$ and clozapine $(5.0 \%)$, and $0.7 \%$ of patients used more than one atypical antipsychotic at study entry. In the ITT analysis, patients receiving more than one atypical antipsychotic had the highest mean annual cost per patient (\$US2355.97 \pm 800.60 ), followed by those receiving olanzapine (\$US2252.59 \pm 547.80 ), clozapine (\$US1909.91 \pm 334.60 ), ziprasidone (\$US1842.44 \pm 809.14), quetiapine (\$US1748.97 \pm 795.15$)$ and risperidone (\$US1195.99 \pm 276.58$)$ (Table 1).

The proportion of patients censoring at the end of follow-up was $86.2 \%$, presenting a mean annual cost per patient of $\$$ US1796.80 \pm 288.20 . However, the mean \pm SD annual cost per patient was higher for individuals who died ( $\$$ US1978.58 \pm 243.14 ). According to the ICD-10 groups, the main causes of death were other degenerative diseases of the nervous system (10.7\%), influenza and pneumonia $(8.7 \%)$ and ischemic heart disease (8.5\%). Patients who had diabetes mellitus recorded as cause of death (4.4\%) had a mean annual cost of $\$$ US2186.81 \pm 581.45 (Table 1).

\subsection{High-Cost Drug Dispensing and Health Services Utilization}

In this cohort, $32.3 \%$ of patients used outpatient care and 20.9\% were hospitalized. High-cost drugs accounted for $84.9 \%$ of total costs in patients with schizophrenia, followed by hospitalizations $(7.8 \%)$ and outpatient care (7.2\%).

Considering the procedure categories, atypical antipsychotics accounted for $79.7 \%$ of the total costs of treating patients, followed by outpatient psychiatric care $(6.0 \%)$ and psychiatric hospitalization (5.6\%). The mean annual cost per patient for atypical antipsychotics was \$US1578.74 \pm 240.40, and the median was \$US1235.86. Mean annual perpatient costs for outpatient psychiatric care and psychiatric hospitalization, respectively, were \$US862.96 \pm 160.18 (median \$US396.52) and \$US2482.90 \pm 302.92 (median \$US1313.94) (Table 2).

Psychiatric treatment accounted for $71.4 \%$ of the total cost for inpatients and for $83.1 \%$ of the total cost for outpatients.

Patients who used olanzapine had the highest mean \pm SD annual costs per patient (\$US2085.28 \pm 485.62; median \$US2006.81) for atypical antipsychotics. Patients who used 
Table 1 Mean annual cost per patient according to clinical and demographic variables of patients with schizophrenia who used atypical antipsychotics provided by the Brazilian

National Health System (SUS). Brazil, 2000-2010 $(n=$ 174,310)

\begin{tabular}{|c|c|c|}
\hline Variables & $N(\%)$ & $\begin{array}{l}\text { Mean annual cost } \pm \text { SD } \\
\text { per patient, } \$ \mathrm{US}\end{array}$ \\
\hline The whole cohort & $174,310(100.0)$ & $1811.92 \pm 284.39$ \\
\hline \multicolumn{3}{|l|}{ Sex } \\
\hline Male & $90,131(51.7)$ & $1914.84 \pm 304.74$ \\
\hline Female & $84,179(48.3)$ & $1672.47 \pm 266.66$ \\
\hline \multicolumn{3}{|l|}{ Age group at study entry, years } \\
\hline $18-25$ & 29,692 (17.0) & $1852.34 \pm 295.58$ \\
\hline $26-35$ & $40,967(23.5)$ & $1892.33 \pm 287.49$ \\
\hline $36-45$ & $39,173(22.5)$ & $1857.03 \pm 316.15$ \\
\hline $46-55$ & $27,626(15.9)$ & $1735.18 \pm 317.17$ \\
\hline $56-65$ & $13,998(8.0)$ & $1669.80 \pm 269.51$ \\
\hline$>65$ & $22,854(13.1)$ & $1397.98 \pm 294.05$ \\
\hline \multicolumn{3}{|l|}{ Geographic region at study entry } \\
\hline Southeast & $112,254(64.4)$ & $1867.57 \pm 287.10$ \\
\hline Northeast & $27,507(15.8)$ & $1727.58 \pm 318.31$ \\
\hline South & $19,091(10.9)$ & $1600.46 \pm 292.30$ \\
\hline Midwest & $12,313(7.1)$ & $1790.39 \pm 283.15$ \\
\hline North & $3145(1.8)$ & $1488.75 \pm 328.43$ \\
\hline \multicolumn{3}{|l|}{ Period of study entry, years } \\
\hline $2000-2003$ & $33,766(19.4)$ & $1957.62 \pm 359.46$ \\
\hline 2004-2007 & $77,894(44.7)$ & $1728.74 \pm 413.57$ \\
\hline 2008-2010 & $62,650(35.9)$ & $1529.68 \pm 526.88$ \\
\hline \multicolumn{3}{|l|}{ Primary diagnosis (ICD-10) at study entry } \\
\hline Paranoid schizophrenia (F20.0) & $115,862(66.5)$ & $1836.89 \pm 315.13$ \\
\hline Simple schizophrenia (F20.6) & 30,771 (17.6) & $1699.74 \pm 411.54$ \\
\hline Other schizophrenia (F20.8) & $11,926(6.8)$ & $1836.30 \pm 384.72$ \\
\hline Residual schizophrenia (F20.5) & $6625(3.8)$ & $1925.06 \pm 347.96$ \\
\hline Hebephrenic schizophrenia (F20.1) & $5152(3.0)$ & $1917.98 \pm 343.57$ \\
\hline Undifferentiated schizophrenia (F20.3) & $2123(1.2)$ & $1647.27 \pm 377.01$ \\
\hline Catatonic schizophrenia (F20.2) & $1000(0.6)$ & $1806.59 \pm 299.28$ \\
\hline Post-schizophrenic depression (F20.4) & $851(0.5)$ & $1774.54 \pm 347.26$ \\
\hline \multicolumn{3}{|l|}{ Atypical antipsychotic at study entry } \\
\hline Olanzapine & $64,652(37.1)$ & $2252.59 \pm 547.80$ \\
\hline Risperidone & $63,361(36.3)$ & $1195.99 \pm 276.58$ \\
\hline Quetiapine & 22,501 (12.9) & $1748.97 \pm 795.15$ \\
\hline Ziprasidone & $13,884(8.0)$ & $1842.44 \pm 809.14$ \\
\hline Clozapine & $8692(5.0)$ & $1909.91 \pm 334.60$ \\
\hline More than one atypical antipsychotic & $1220(0.7)$ & $2355.97 \pm 800.60$ \\
\hline \multicolumn{3}{|l|}{ Events } \\
\hline Drug switching & $48,648(27.9)$ & $2161.56 \pm 276.57$ \\
\hline Psychotic outbreak & $25,213(14.5)$ & $2313.06 \pm 399.41$ \\
\hline \multicolumn{3}{|l|}{ End of follow-up } \\
\hline Censoring & $150,270(86.2)$ & $1796.80 \pm 288.20$ \\
\hline Death & $24,040(13.8)$ & $1978.58 \pm 243.14$ \\
\hline \multicolumn{3}{|l|}{ Cause of death (ICD-10 groups) } \\
\hline Other degenerative diseases of the NS & 2585 (10.7) & $1604.01 \pm 330.28$ \\
\hline Influenza and pneumonia & $2089(8.7)$ & $1823.03 \pm 461.70$ \\
\hline Ischemic heart disease & $2055(8.5)$ & $1574.67 \pm 306.82$ \\
\hline Cerebrovascular diseases & $1897(7.9)$ & $1986.59 \pm 343.62$ \\
\hline Unclear cause & $1245(5.2)$ & $1810.94 \pm 323.80)$ \\
\hline Diabetes mellitus & $1049(4.4)$ & $2186.81 \pm 581.45$ \\
\hline Other groups & $13,120(54.6)$ & $2069.47 \pm 262.92$ \\
\hline
\end{tabular}

Values were converted to \$US and adjusted using the purchasing power parity rate (World Bank)

ICD-10 International Statistical Classification of Diseases and Related Health Problems, Tenth Revision; $N S$ nervous system, $S D$ standard deviation 
Table 2 Cost per patient receiving schizophrenia treatment, according to the category of procedure during the follow-up period. Brazil, 2000-2010 $(n=174,310)$

\begin{tabular}{lcccc}
\hline Category of procedure & Patients, $N(\%)$ & Cost $(\$ \mathrm{US})$ & & \\
\cline { 3 - 5 } & & $\operatorname{Mean}^{\mathrm{a}}(\mathrm{SD})$ & $\operatorname{Median}^{\mathrm{b}}(\mathrm{IQR} 1 ;$ IQR 3) & $\%^{\mathrm{c}}$ \\
\hline Atypical antipsychotics & $174,310(100.0)$ & $1578.74(240.40)$ & $1235.86(1001.12 ; 1341.90)$ & 79.7 \\
Outpatient psychiatric care & $30,292(17.4)$ & $862.96(160.18)$ & $396.52(342.01 ; 420.31)$ & 6.0 \\
Psychiatric hospitalization & $19,212(11.0)$ & $2482.90(302.92)$ & $1313.94(1283.82 ; 1344.95)$ & 5.6 \\
Other high-cost drugs & $26,820(15.4)$ & $924.04(151.07)$ & $272.58(189.00 ; 537.54)$ & 5.2 \\
Other hospitalizations & $20,834(12.0)$ & $1266.99(201.58)$ & $450.07(420.17 ; 453.16)$ & 2.2 \\
Other outpatient care & $31,330(18.0)$ & $345.75(35.80)$ & $50.32(39.75 ; 63.52)$ & 1.2 \\
\hline
\end{tabular}

Values were converted to \$US and adjusted using the purchasing power parity rate (World Bank)

$I Q R$ interquartile range, $S D$ standard deviation

${ }^{a}$ Mean annual cost per patient

${ }^{\mathrm{b}}$ Median annual cost per patient

${ }^{c}$ Proportion of total costs clozapine had the highest mean annual cost per patient (\$US1105.39 \pm 236.70 ; median \$US550.60) for outpatient psychiatric care and the highest mean annual cost per patient (\$US3509.34 \pm 854.21 ; median \$US1842.45) for psychiatric hospitalization (Table 3).

Patients who used risperidone consumed the highest percentage (20.1\%) of outpatient psychiatric care, and $14.1 \%$ of those who used clozapine underwent at least one psychiatric hospitalization. Patients who used quetiapine had the lowest percentage of outpatient psychiatric care (9.7\%) and psychiatric hospitalizations (6.4\%). However, patients who used quetiapine used the highest percentage of other high-cost drugs $(31.0 \%)$ (Table 3$)$.

Most patients (72.1\%) remained on their atypical antipsychotic at study entry. The highest percentage of permanence on atypical antipsychotic treatment was observed for patients receiving olanzapine (27.9\%), followed by those receiving risperidone (25.4\%), quetiapine (10.3\%), ziprasidone $(5.0 \%)$ and clozapine (3.6\%).

During the 11-year follow-up, the mean annual cost per patient for hospital procedures appeared to generally increase, with an emphasis on psychiatric hospitalizations. On the other hand, the mean annual cost per patient with high-cost drugs, such as atypical antipsychotics, and outpatient care, such as outpatient psychiatric care, tended to fall (Fig. 1).

\subsection{Multivariate Analysis}

Male patients were associated with an increase of approximately $11 \%$ in the mean annual costs per patient (PD 11.51, $p<0.001$ ), whereas patients aged $46-65$ years were associated with a decrease in mean annual costs per patient. The variables drug switching $(103.07, p<0.001)$, psychotic outbreak $(52.89, p<0.001)$, comorbidities $(19.37, p<0.001)$ and death $(32.22, p<0.001)$ were also associated with an increase in the mean annual costs per patient (Fig. 2).
For each year in the cohort, an increase of approximately $7 \%$ in the mean annual costs per patient $(6.61, p<0.001)$ was observed, and registration of psychiatric care before starting the antipsychotic treatment was associated with an increase of approximately $25 \%$ in the mean annual costs per patient $(25.14, p<0.001)$ (Fig. 2).

Patients who used risperidone at study entry were associated with a reduction of approximately $81 \%$ in the mean annual costs per patient $(-80.94, p<0.001)$ compared with patients who used more than one atypical antipsychotic at study entry. Conversely, the use of clozapine $(10.31, p<$ 0.01 ), olanzapine $(83.13, p<0.001)$, quetiapine $(64.04, p<$ $0.001)$ and ziprasidone $(70.64, p<0.001)$ at study entry was associated with an increase in mean annual costs per patient.

Furthermore, patients who used other high-cost drugs during follow-up presented an increase of $60 \%$ in the mean annual costs per patient $(60.00, p<0.001)$ (Fig. 2).

Approximately $51 \%\left(R^{2}=0.5099\right)$ of the variability of the mean annual cost per patient was explained by the best fitted model $(p<0.001)$ (Table S1 in the ESM, and Fig. 2).

\section{Discussion}

In this study, we identified and described the treatment costs of more than 174,000 patients who used atypical antipsychotic drugs for schizophrenia through the Brazilian NHS (SUS). The literature surrounding the treatment of schizophrenia in the real world is scarce, and this study was undertaken to address this issue in Brazil using large administrative databases (big data) as an information source. Although the term big data has gained prominence in recent years, its use in health economics and outcomes research requires further encouragement [35]. With regard to the optimization of financial resources, we believe the results of this study will encourage national health services in Brazil and globally to focus on policies aimed at improving the rational use of 


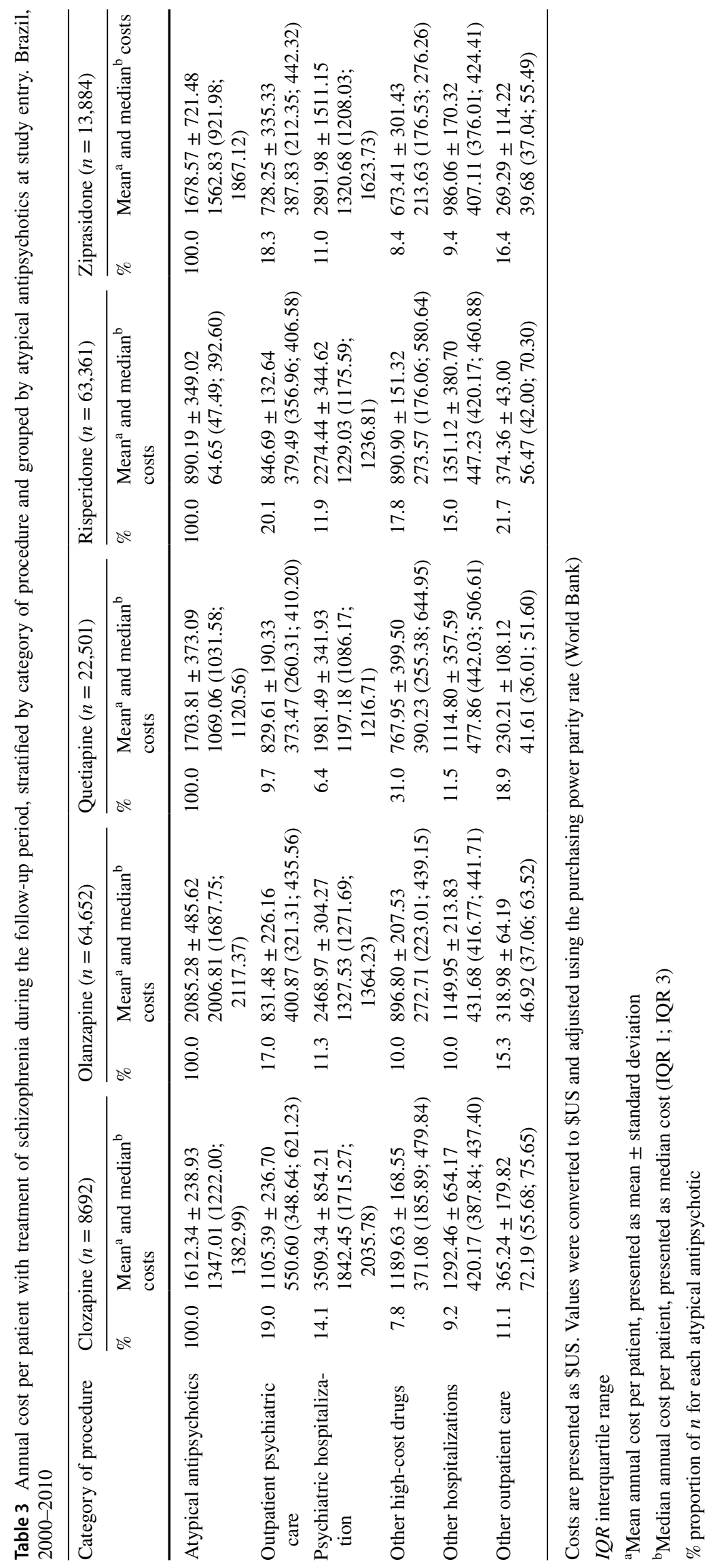


Fig. 1 Mean annual cost per patient according to the procedure category and the year of follow-up, adjusted by the purchasing power parity rate. Brazil, 2000-2010

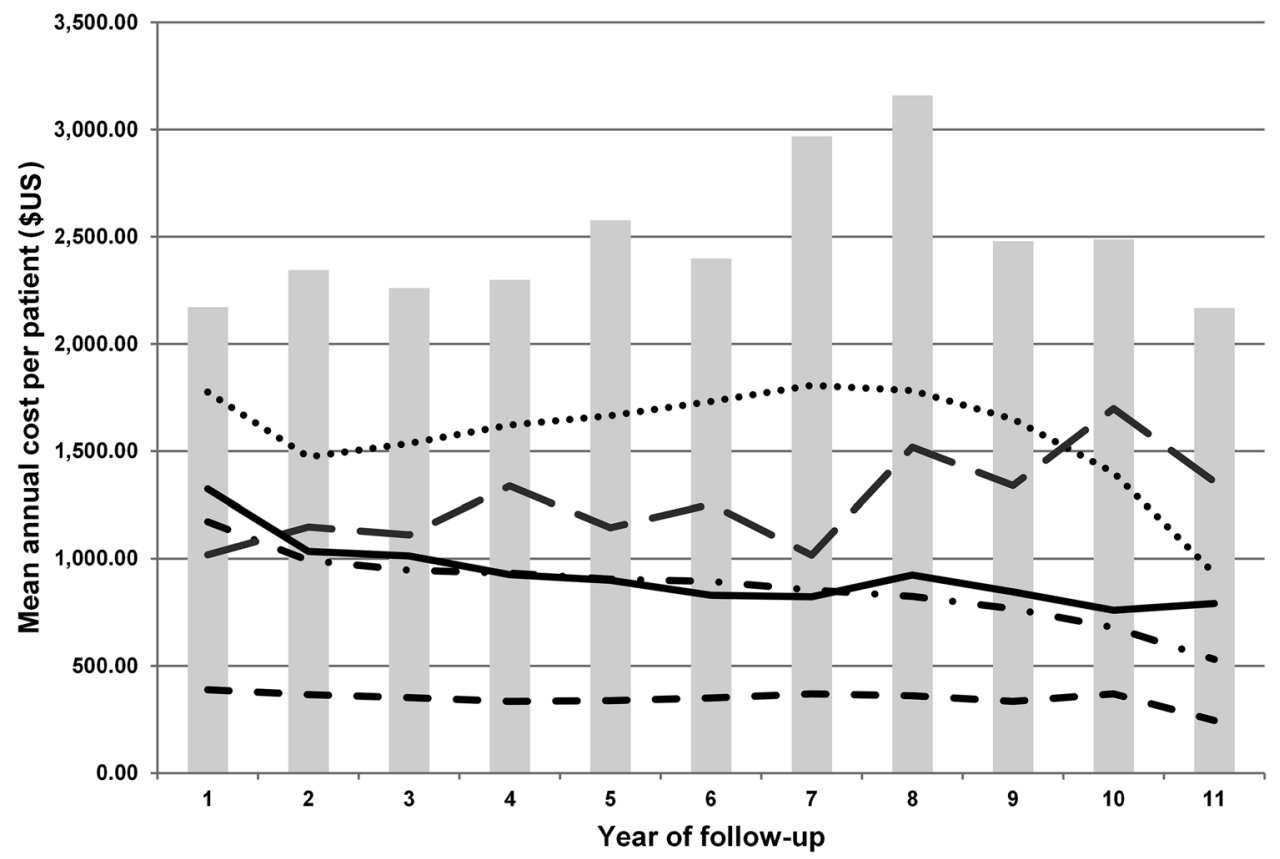

Psychiatric hospitalizations - • O Outpatient psychiatric care -.... Atypical antipsychotics

- Other hospitalizations
- Other outpatient care atypical antipsychotic medicines with increasing availability of generic oral antipsychotic medicines and the use of outpatient psychiatric care over psychiatric hospitalizations where possible.

During the 11-year follow-up of patients with schizophrenia receiving atypical antipsychotics, these drugs represented the largest proportion of direct healthcare costs in the treatment of schizophrenia. Overall, the cost of medicines was responsible for approximately $85 \%$ of the total direct medical costs (Table 2) and was the main determinant of the mean annual cost per patient (Table S1 in the ESM, and Fig. 2). Knapp et al. [36] conducted a systematic review and showed that, in general, spending on medicines in countries with higher incomes ranged from 1.1 to $9.0 \%$ of all direct healthcare costs in patients with schizophrenia and that this difference was related to the extent and methods by which expenditures were determined, the pricing policies, the available medicines and the health service structure of each country. According to their systematic review, the cost of medicines tends to be higher in countries where services are more limited and where the cost of inpatient treatment is lower. However, the reviewed papers were published between 1992 and 1997, before atypical antipsychotics and care in the community became established [36].

Our findings contrast with those from more recent studies that indicated medicine costs accounted for approximately $25 \%$ of direct healthcare costs of patients with schizophrenia [6, 7, 14]. In Brazil, Razzouk et al. [18] stated that spending on antipsychotic drugs in patients with psychotic disorders may account for about $50 \%$ of direct health costs in the SUS. Even considering the methodological particularities of the cost studies, mainly with regard to the cost components of each, one reason for the higher burden of medicines in our study could be that some patients are receiving their pharmacotherapy via the SUS and using the private sector (health plan or direct payment) for outpatient and hospital treatment, since health plans in Brazil usually do not provide for continuous use medication such as antipsychotic drugs. In 2000, a total of $18.2 \%$ of the Brazilian population had a private health plan, and this increased to $23.6 \%$ in 2010 [37, 38]. Another fact that may well have influenced these costs is that, between 2000 and 2010, the period of this cohort, many atypical antipsychotics were under patent protection (originator antipsychotics); this is changing, and their related mean annual expenditure per patient is now falling (Fig. 1) as seen with risperidone. Studies analysing antipsychotic prescriptions over time have also shown a decrease in expenditure. For example, the costs of risperidone appreciably fell in Western Europe after generics became available. This was also often accompanied by a fall in the price of originator risperidone [39-43].

Several studies have compared atypical antipsychotics and found medication-specific adverse reactions, which could affect costs, and limited differences with respect to their efficacy [44-49]. Based on these differences, some studies have questioned the utility of broadly characterizing new-generation antipsychotic drugs as atypicals, as these drugs are not homogeneous $[50,51]$. Thus, it is clear that 


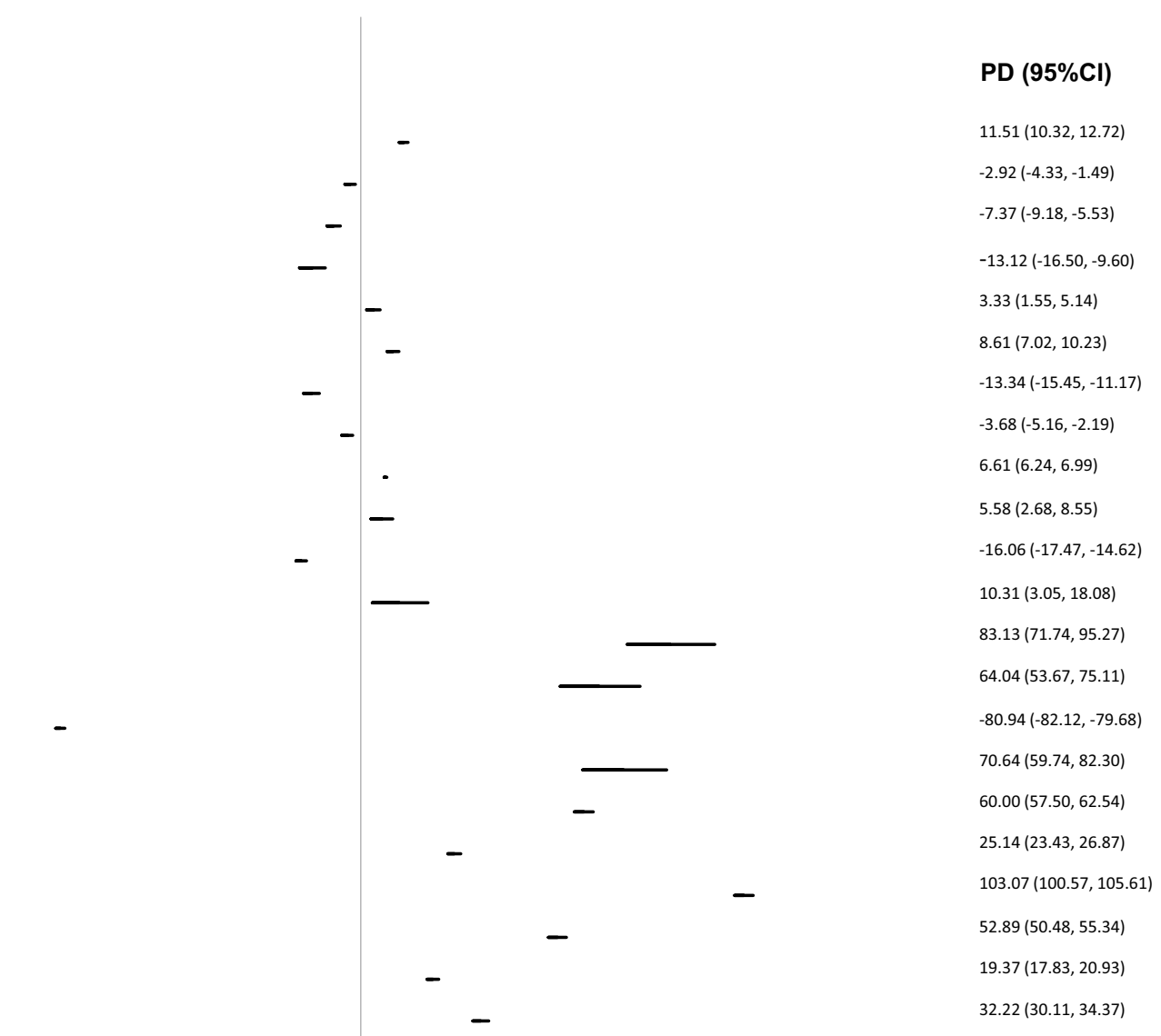

\begin{tabular}{rrrrrrrr}
\hline-90 & -60 & -30 & 0 & 30 & 60 & 90 & 120
\end{tabular}

AA, atypical antipsychotic; CLO, clozapine; OLA, olanzapine; QUE, quetiapine; RIS, risperidone; ZIP, ziprasidone

Fig. 2 Forest plot showing percentage difference of the mean annual cost per patient with $95 \%$ confidence intervals from the multivariate log-linear regression model. Brazil, 2000-2010. AA atypical antipsy-

additional studies are needed to better understand the difference in the percentage of total cost and the mean annual cost per patient for atypical antipsychotic drugs, especially between olanzapine and risperidone, building on our findings. New studies will further assist decision makers in allocating healthcare resources and understanding whether differences in the mean annual costs per patient for the different atypical antipsychotics are accompanied by benefits for patients, their families and the general population. Having said this, we are aware that the atypical antipsychotic treatments chosen should be based on the characteristics of both the patient and the medicine rather than advocating a particular atypical antipsychotic as first-line treatment [52, 53]. This is apart from clozapine, which is typically reserved for refractory cases.

In Brazil, unlike previous clinical protocols guiding schizophrenia treatment during the period of this cohort $[9,10]$, the current clinical guideline does not recommend chotic, $C I$ confidence interval, $C L O$ clozapine, $O L A$ olanzapine, $P D$ percentage difference, $Q U E$ quetiapine, RIS risperidone, ZIP ziprasidone

a specific treatment pathway [11], similar to other guidelines $[3,8]$. The only exception in Brazil is regarding clozapine, which must be prescribed only for refractory cases [11], again similar to guidelines in other countries. This recommendation is mainly based on its adverse effects and tolerability profile [11, 48]. In our study, clozapine accounted for the highest average annual cost per patient due to psychiatric hospitalizations and outpatient psychiatric care. This suggests that patients treated with clozapine have complicated disease that is refractory to other medications, which aligns with current clinical guidelines. Patients with disease that is refractory to other antipsychotic drugs, or who have lower adherence to drug therapy, may have psychotic outbreaks and need hospitalization or outpatient care, contributing to increased costs. However, this needs to be shown in additional studies before any definitive statement can be made. Having said this, drug 
switching and psychotic outbreaks were associated with an increase in the mean annual cost per patient in our study.

Psychiatric hospitalization resulted in the highest mean annual cost per patient and showed a growth trend during the follow-up years (Fig. 1). Since the 1970s, Brazil has been following the development of a complex political and social process called the Psychiatric Reform, which encourages dehospitalisation of patients with mental disorders, directing these patients to community treatment, with an emphasis on outpatient care [54-56]. The results in this cohort reinforce the dehospitalisation policy for psychiatric patients in Brazil since outpatient psychiatric care had the lowest mean annual cost per patient, with a tendency for these costs to be reduced during the follow-up years (Fig. 1). In view of this, improving ambulatory care management of patients with schizophrenia is an essential component to optimize the use of available resources. We will be researching this in Brazil in the future, including looking more closely at adherence rates for atypical antipsychotics in routine ambulatory care, with relapses appreciably increasing costs [57]. This further research will build on our initial findings.

We accept that, since this cohort was established from administrative databases, information may be incomplete or inconsistent, problems that are inherent to retrospective studies using secondary databases. This means that some clinical information is missing, such as time of diagnosis, information using the Positive and Negative Syndrome Scale and the Brief Psychiatric Rating Scale, and reasons for switching atypical antipsychotics. Furthermore, the tabulated values are taken directly from the SUS database (SIA and $\mathrm{SIH}$ ) and were not further validated after the data were entered onto the national systems and represent an estimate of actual costs because they are the amounts reimbursed by the federal government. We also could not include the costs of typical antipsychotics that were not included in the SUS database. Finally, we are aware that some patients used the private sector (health plan or direct payment) for outpatient and hospital treatment, which potentially distorts our findings. Despite these limitations, we believe our comprehensive methodology has led to robust findings that provide direction for the future.

\section{Conclusion}

In this 11-year nationwide cohort, high-cost drugs, including atypical antipsychotics, drug switching and psychotic outbreaks, were the principal contributors to the mean annual costs per patient with schizophrenia, with atypical antipsychotics responsible for the majority of direct costs. However, this is influenced by the availability of generally only patented atypical antipsychotics (antipsychotic originator) during the study period. Psychiatric hospitalization was associated with a higher mean annual cost per patient than were atypical antipsychotics and outpatient psychiatric care and should be avoided where possible by improving ambulatory care services. Patients prescribed clozapine had the highest mean annual cost per patient for outpatient psychiatric care and psychiatric hospitalization, suggesting these patients have complicated disease requiring additional attention, including hospitalization.

It is important to highlight that public policies and decision making should not be based exclusively on costs and should also consider outcomes and health indicators. Lastly, the results of this analysis of real-world data can be used to inform future strategies of the NHS, in Brazil and globally, and suggests a need to ensure effective use of atypical antipsychotics and encourage outpatient psychiatric care where possible to reduce psychiatric hospitalization.

Data Availability Statement The SUS database is owned by the epidemiological, economic and care evaluation trajectories of high-cost procedures in the SUS: use of a patientcentred database based on the integration of health information systems records in Brazil Government, and access is very tightly controlled. No data can be analysed apart from by approved research institutions in Brazil, with strict access criteria and controls. This is similar to the ability to access patient-level data in other countries such as Scotland and Sweden.

Author contributions WBB, JdeOC, LLPdeL, RMG and AAG Jr designed the study. WBB and AAG Jr conducted the study. WBB, JdeOC and RMG performed the statistical analyses. WBB, JdeOC, LLPdeL, BG and RMG produced the initial draft. WBB, JdeOC, LLPdeL, RMG, HNdeO, CMR, FdeAA, CB, MB, BG and AAG Jr contributed to successive versions before submission. WBB, JdeOC, LLPdeL, RMG, FdeAA, MB, BG and AAG Jr contributed to the revised paper following reviewer comments.

\section{Compliance with Ethical Standards}

Funding No sources of funding were used to conduct this study or prepare this manuscript.

Conflict of interest WBB, JdeOC, LLPdeL, RMG, HNdeO, CMR, FdeAA, CB, MB, BG and AAG Jr have no conflicts of interest.

Open Access This article is distributed under the terms of the Creative Commons Attribution-NonCommercial 4.0 International License (http://creativecommons.org/licenses/by-nc/4.0/), which permits any noncommercial use, distribution, and reproduction in any medium, provided you give appropriate credit to the original author(s) and the source, provide a link to the Creative Commons license, and indicate if changes were made. 


\section{References}

1. American Psychiatric Association. Diagnostic and statistical manual of mental disorders. 5th ed. Arlington: American Psychiatric Association; 2013.

2. Whiteford HA, Degenhardt L, Rehm J, et al. Global burden of disease attributable to mental and substance use disorders: findings from the Global Burden of Disease Study 2010. Lancet. 2013;382:1575-86.

3. National Institute for Health and Care Excellence. Clinical guideline [CG178]. Psychosis and schizophrenia in adults: prevention and management. National Institute for Health and Care Excellence, 2014.

4. National Institute of Mental Health. Health and education. 2017. https://www.nimh.nih.gov/health/topics/schizophrenia/index .shtml. Accessed Dec 2017.

5. Wu EQ, Birnbaum HG, Shi L, et al. The economic burden of schizophrenia in the United States in 2002. J Clin Psychiatry. 2005;66(9):1122-9.

6. Cloutier M, Aigbogun MS, Guerin A, et al. The Economic Burden of Schizophrenia in the United States in 2013. J Clin Psychiatry. 2016;77(6):764-71.

7. Fitch K, Iwasaki K, Villa KF. Resource utilization and cost in a commercially insured population with schizophrenia. Am Health Drug Benefits. 2014;7(1):18-26.

8. Lehman AF, Lieberman JA, Dixon LB, et al. Practice guideline for the treatment of patients with schizophrenia. Am J Psychiatry. 2004;161:1-56.

9. Brasil. Ministério da Saúde. Secretaria de Assistência à Saúde. Portaria $\mathrm{n}^{\circ}$ 345, de 15 de maio de 2002. Esquizofrenia Refratária. Diário Oficial da União, 15 mai 2002.

10. Brasil. Ministério da Saúde. Secretaria de Assistência à Saúde. Portaria $n^{\circ} 846$, de 31 de outubro de 2002. Diário Oficial da União, 04 nov 2002.

11. Brasil. Ministério da Saúde. Portaria $n^{\circ} 364$, de 09 de abril de 2013. Aprova o Protocolo Clínico e Diretrizes Terapêuticas-Esquizofrenia.

12. Brasil. Ministério da Saúde. Secretaria de Ciência, Tecnologia e Insumos Estratégicos. Componente Especializado da Assistência Farmacêutica: inovação para a garantia do acesso a medicamentos no SUS. Brasília: Ministério da Saúde, 2014.

13. Brasil. Ministério da Saúde. Da excepcionalidade às linhas de cuidado: o componente especializado da assistência farmacêutica. Brasília: Ministério da Saúde, 2010.

14. Degli Esposti L, Sangiorgi D, Mencacci C, et al. Pharmacoutilisation and related costs of drugs used to treat schizophrenia and bipolar disorder in Italy: the IBIS study. BMC Psychiatry. 2014; $14: 282$.

15. Acurcio FdA, Brandão CMR, Guerra Júnior AA, et al. Epidemiological profile of high cost medicines users in the Brazilian Health System. Rev bras estud popul. 2009;26:263-82.

16. World Bank, International Comparison Program database. 2017. http://data.worldbank.org/indicator/PA.NUS. PPP?end $=2016 \&$ locations $=$ BR\&start $=2000$. Accessed $20 \mathrm{Jul}$ 2017.

17. Lindner LM, Marasciulo AC, Farias MR, Grohs GEM. Economic evaluation of antipsychotic drugs for schizophrenia treatment within the Brazilian Healthcare System. Rev Saúde Pública. 2009;43(Suppl. 1):62-9.

18. Razzouk D, Kayo M, Sousa A, et al. The impact of antipsychotic polytherapy costs in the public health care in Sao Paulo, Brazil. PLoS One. 2015;10(4):e0124791.

19. Santos AS, Vidal CEL, Brandao CMR. Cost-effectiveness of atypical antipsychotics for the treatment of schizophrenia. J Bras Econ Saúde. 2016;8(3):204-15.
20. Brasil. Ministério da Saúde. Secretaria de Assistência à Saúde. Portaria no 204, de 6 de outubro de 1996. Cria novos códigos de medicamentos excepcionais na Tabela Descritiva de Procedimentos do SIA/SUS. Diário Oficial da União, Poder Executivo, Brasília, DF, 18 de novembro de 1996.

21. Brasil. Ministério da Saúde. Gabinete do Ministro. Portaria no 1.230, de 14 de outubro de 1999. Diário Oficial da União, Poder Executivo, Brasília, DF, 18 de outubro de 1999.

22. Brasil. Ministério da Saúde. Secretaria de Assistência à Saúde. Portaria $n^{\circ}$ 346, de 14 de maio de 2002. Diário Oficial da União, 15 mai 2002.

23. Brasil. Ministério da Saúde. Secretaria de Assistência à Saúde. Portaria ${ }^{\circ} 1318$, de 23 de julho de 2002. Diário Oficial da União, 24 jul 2002.

24. Agência Nacional de Vigilância Sanitária. 2018. http://portal.anvis a.gov.br/. Accessed 07 May 2018.

25. Cherchiglia ML, Guerra Júnior AA, Andrade EIG, et al. A construção da base de dados nacional em terapia renal substitutiva (TRS) centrada no indivíduo: aplicação do método de linkage determinístico-probabilístico. Revista Brasileira de Estudos de População. 2007;24:163-7.

26. Pereira R, Dias L, Ávila J, et al. Unified health database creation: 125 million brazilian cohort from information systems of hospital, outpatient, births, notifications and mortalities. Int J Popul Data Sci. 2017;1(1):1-225.

27. Queiroz OV, Guerra AA Jr., Machado CJ, et al. Building the National Database on Renal Replacement Therapy Focused on the Individual: Probabilistic Record Linkage of Death Registries at the High Complexity Procedures Authorization subsystem (Apac/SIA/SUS) and at the Mortality Information System (SIM)-Brazil, 2000-2004. Epidemiol Serv Saúde. Brasília. 2009;18(2):107-20.

28. Coeli CM, Camargo Jr KRD. Evaluation of different blocking strategies in probabilistic record linkage. Rev Bras Epidemiol. 2002;5:185-96.

29. Brasil. Ministério da Saúde. Secretaria de Atenção à Saúde. Departamento de Regulação, Avaliação e Controle. Coordenação Geral de Sistemas de Informação. SIA - Sistema de Informação Ambulatorial do SUS: Manual de Operação do Sistema. Brasília: Ministério da Saúde, 2016.

30. Brasil. Ministério da Saúde. Secretaria de Atenção à Saúde. Departamento de Regulação, Avaliação e Controle. Coordenação Geral de Sistemas de Informação. SIH - Sistema de Informação Hospitalar do SUS: Manual de Operacional do Sistema. Brasília: Ministério da Saúde, 2017.

31. Brasil. Ministério da Saúde. Secretaria de Ciência, Tecnologia e Insumos Estratégicos. Departamento de Ciência e Tecnologia. Diretrizes Metodológicas : estudos de avaliação econômica de tecnologias em saúde / Ministério da Saúde, Secretaria de Ciência, Tecnologia e Insumos Estratégicos, Departamento de Ciência e Tecnologia. - Brasília: Ministério da Saúde, 2009.

32. Brasil. Ministério da Saúde 2018. http://portalms.saude.gov.br/ sistema-unico-de-saude. Accessed 4 May 2018.

33. Elixhauser A, Steiner C, Harris DR, Coffey RM. Comorbidity measures for use with administrative data. Med Care. 1998;36(1):8-27.

34. Quan H, Sundararajan V, Halfon P, et al. Coding algorithms for defining comorbidities in ICD-9-CM and ICD-10 administrative data. Med Care. 2005;43(11):1130-9.

35. Onukwugha E. Big data and its role in health economics and outcomes research: a collection of perspectives on data sources, measurement, and analysis. Pharmacoeconomics. 2016;34:91-3.

36. Knapp M, Mangalore R, Simon J. The global costs of schizophrenia. Schizophr Bull. 2004;30:279-93. 
37. Brasil. Ministério da Saúde. Agência Nacional de Saúde Suplementar. Caderno de Informação da Saúde Suplementar: beneficiários, operadoras e planos. Brasília-DF: ANS; 2016.

38. Instituto Brasileiro de Geografia e Estatística. 2017. http://bibli oteca.ibge.gov.br/visualizacao/livros/liv64529_apres_intr.pdf. Accessed 13 Mar 2017.

39. Godman B, Bucsics A, Burkhardt T, et al. Potential to enhance the prescribing of generic drugs in patients with mental health problems in Austria; implications for the future. Front Pharmacol. 2012;3:198.

40. Godman B, Persson M, Miranda J, et al. Can authorities take advantage of the availability of generic atypical antipsychotic drugs? Findings from Sweden and potential implications. JPHSR. 2013;4:139-50.

41. Godman B, De Bruyn K, Miranda J, et al. Generic atypical antipsychotic drugs in Belgium: their influence and implications. J Comp Eff Res. 2013;2(6):551-61.

42. Bennie M, Bishop I, Godman B, et al. Are specific initiatives required to enhance prescribing of generic atypical antipsychotics in Scotland?: International implications. Int J Clin Pract. 2013;67(2):170-80.

43. Godman B, Petzold M, Bennett K, et al. Can authorities appreciably enhance the prescribing of oral generic risperidone to conserve resources? Findings from across Europe and their implications. BMC Med. 2014;13(12):98.

44. Komossa K, Rummel-Kluge $\mathrm{C}$, Hunger $\mathrm{H}$, et al. Olanzapine versus other atypical antipsychotics for schizophrenia. Cochrane Database Syst Rev. 2010. https://doi.org/10.1002/14651858.CD006 654.pub2.

45. Komossa K, Rummel-Kluge C, Schwarz S, et al. Risperidone versus other atypical antipsychotics for schizophrenia. Cochrane Database Syst Rev. 2011. https://doi.org/10.1002/14651858. CD006626.pub2.

46. Asmal L, Flegar SJ, Wang J, et al. Quetiapine versus other atypical antipsychotics for schizophrenia. Cochrane Database Syst Rev. 2013;11:006625.

47. Greenberg WM, Citrome L. Ziprasidone for schizophrenia and bipolar disorder: a review of the clinical trials. CNS Drug Rev. 2007;13:137-77.
48. Asenjo Lobos C, Komossa K, Rummel-Kluge C, et al. Clozapine versus other atypical antipsychotics for schizophrenia. Cochrane Database Syst Rev. 2010. https://doi.org/10.1002/14651858. CD006633.pub2.

49. Barbui C, Baschirotto C, Cipriani A. Review: is aripiprazole as effective as risperidone in people with schizophrenia? Evid Based Ment Health. 2010;13(2):51.

50. Leucht S, Corves C, Arbter D, et al. Second-generation versus first-generation antipsychotic drugs for schizophrenia: a metaanalysis. Lancet. 2009;373:31-41.

51. Leucht S, Cipriani A, Spineli L, et al. Comparative efficacy and tolerability of 15 antipsychotic drugs in schizophrenia: a multipletreatments meta-analysis. Lancet. 2013;382(9896):951-62.

52. Godman B, Petzold M, Bennett K, et al. Can authorities appreciably enhance the prescribing of oral generic risperidone to conserve resources? Findings from across Europe and their implications. BMC Med. 2014;12:98.

53. Parks J, Radke A, Parker G, et al. Principles of antipsychotic prescribing for policy makers, circa 2008. Translating knowledge to promote individualized treatment. Schizophr Bull. 2009;35(5):931-6.

54. Brasil. Ministério da Saúde. Lei ${ }^{\circ}$ 10.216, de 6 de abril de 2001. Dispõe sobre a proteção e os direitos das pessoas portadoras de transtornos mentais e redireciona o modelo assistencial em saúde mental. Diário Oficial da União. 09 abr 2001.

55. Brasil. Ministério da Saúde. Secretaria de Atenção à Saúde. DAPE. Reforma psiquiátrica e política de saúde mental no Brasil. Brasília, novembro de 2005.

56. Razzouk D. Accommodation and health costs of deinstitutionalized people with mental illness living in residential services in Brazil. Pharmacoecon Open. 2018. https://doi.org/10.1007/s4166 9-018-0078z.

57. Lafeuille MH, Gravel J, Lefebvre P, et al. Patterns of relapse and associated cost burden in schizophrenia patients receiving atypical antipsychotics. J Med Econ. 2013;16(11):1290-9.

\section{Affiliations}

\section{Wallace Breno Barbosa ${ }^{1,2}$. Juliana de Oliveira Costa ${ }^{2,3}$. Lívia Lovato Pires de Lemos ${ }^{2,3} \cdot$ Rosângela Maria Gomes ${ }^{1,2}$. Helian Nunes de Oliveira $^{3}$. Cristina Mariano Ruas ${ }^{1}$. Francisco de Assis Acurcio ${ }^{1,2}$. Corrado Barbui ${ }^{4}$. Marion Bennie ${ }^{5}$. Brian Godman ${ }^{5,6,7,8}$. Augusto Afonso Guerra $\mathrm{Jr}^{1,2}$}

\author{
Wallace Breno Barbosa \\ wallacebrenobarbosa@gmail.com \\ Juliana de Oliveira Costa \\ juliana.olic@gmail.com \\ Lívia Lovato Pires de Lemos \\ lilolemos@gmail.com \\ Rosângela Maria Gomes \\ rosangelamgomes@gmail.com \\ Helian Nunes de Oliveira \\ heliannunes@gmail.com \\ Cristina Mariano Ruas \\ crisruasufmg@gmail.com \\ Francisco de Assis Acurcio \\ fracurcio@gmail.com
}

Corrado Barbui

corrado.barbui@univr.it

Marion Bennie

marion.bennie@strath.ac.uk

Augusto Afonso Guerra Jr augustoguerramg@gmail.com

1 Department of Social Pharmacy, College of Pharmacy, Federal University of Minas Gerais, Av. Presidente Antônio Carlos, 6627, Campus Pampulha, Belo Horizonte, MG 31270-901, Brazil

2 SUS Collaborating Centre-Technology Assessment and Excellence in Health (CCATES/UFMG), College of Pharmacy, Federal University of Minas Gerais, Av. Presidente Antônio Carlos, 6627, Campus Pampulha, Belo Horizonte, MG 31270-901, Brazil 
3 Department of Preventive and Social Medicine, College of Medicine, Federal University of Minas Gerais, Av. Prof. Alfredo Balena, 190, Santa Efigênia, Belo Horizonte, MG 30130-100, Brazil

4 WHO Collaborating Centre for Research and Training in Mental Health and Service Evaluation, Department of Neuroscience, Biomedicine and Movement Sciences, Section of Psychiatry, University of Verona, Verona, Italy

5 Strathclyde Institute of Pharmacy and Biomedical Sciences, Strathclyde University, Glasgow G4 0RE, United Kingdom
6 Health Economics Centre, Liverpool University Management School, Chatham Street, Liverpool, UK

7 Division of Clinical Pharmacology, Department of Laboratory Medicine, Karolinska Institute, Karolinska University Hospital Huddinge, 14186 Stockholm, Sweden

8 School of Pharmacy, Sefako Makgatho Health Sciences University, Molotlegi Street, Ga-Rankuwa, Pretoria, South Africa 